\title{
Molecular forms of Anopheles subpictus s.l. and Anopheles sundaicus s.l. in the Indian subcontinent
}

\author{
Ankita Sindhania ${ }^{1}$, Manoj K. Das ${ }^{2}$, Gunjan Sharma ${ }^{1}$, Sinnathamby N. Surendran ${ }^{3}$, B.R. \\ Kaushal $^{4}$, Himanshu P. Lohani ${ }^{4}$, Om P. Singh ${ }^{1}$ * \\ ${ }^{1}$ National Institute of Malaria Research, Sector 8 Dwarka, New Delhi 110077, India \\ ${ }^{2}$ National Institute of Malaria Research, Field Unit, Itki, Ranchi-835301, India \\ ${ }^{3}$ Department of Zoology, University of Jaffna, Jaffna 40000, Sri Lanka \\ ${ }^{4}$ Department of Zoology, Kumaun University, Nainital, India
}

*Correspondence: $\underline{\text { singh@ @nimr.org.in }}$

Emails:

AS: ankitasindhania@gmail.com

MKD: manojdas2003@yahoo.co.in

GS: guunjan.sharma@gmail.com

SNS: noble@univ.jfn.ac.lk

BRK: brkaushal01@gmail.com

HPL: dr.himanshulohani@gmail.com

OPS: singh@nimr.org.in

\begin{abstract}
Background: Anopheles subpictus s.l. and Anopheles sundaicus s.l. are closely related species, each comprising of several sibling species. Ambiguities exist in the classification of these two nominal species and the specific status of members of An. subpictus complex. Identifying fixed molecular forms and mapping their spatial distribution will help in resolving the taxonomic ambiguities and understanding their relative epidemiological significance.
\end{abstract}

Methods: DNA sequencing of Internal Transcribed Spacer-2 (ITS2), 28S-rDNA (D1-to-D3 
domains) and cytochrome oxidase-II of morphologically identified specimens of two nominal species, An. subpictus s.l. and An. sundaicus s.l. collected from the Indian subcontinent, was performed and subjected to genetic distance and molecular phylogenetic analyses.

Results: Molecular characterization of mosquitoes for rDNA revealed the presence of two molecular forms of An. sundaicus s.l. (identified as An. epiroticus s.s. and An. sundaicus D) and three molecular forms of An. subpictus s.l. (provisionally designated as Form A, B and C) in the Indian subcontinent. Phylogenetic analyses revealed two distinct clades: (i) subpictus clade, with a single molecular form of An. subpictus (Form A) prevalent in mainland India and Sri Lanka, and (ii) sundaicus clade, comprising of members of Sundaicus Complex., two molecular forms of An. subpictus s.l., (Form B and C) prevalent in coastal areas or islands, and molecular forms reported from Thailand and Indonesia. Based on the number of floatridges on eggs, all An. subpictus molecular Form B were classified as Species B whereas majority (80\%) of the molecular Form A were classified as sibling species C. Fixed intragenomic sequence variation in ITS2 with the presence of two haplotypes was found in molecular Form A throughout its distribution.

Conclusion: A total of three molecular forms of An. subpictus s.l. and two molecular forms of An. sundaicus s.l. were recorded in the Indian subcontinent. Phylogenetically, two forms of An. subpictus s.l., (Form B and C) prevalent in coastal areas or islands in the Indian subcontinent and molecular forms reported from Southeast Asia are members of Sundaicus Complex. Molecular Form A of An. subpictus is distantly related to all other forms and deserve a distinct specific status. Presence of An. epiroticus in Indian territory is recorded for the first time.

Keywords: Anopheles subpictus, Anopheles sundaicus, sibling species, species complex, phylogenetics, ribosomal DNA

\section{Background}

Anopheles subpictus sensu lato and Anopheles sundaicus sensu lato are closely related species belonging to Pyretophorus Series [1] and each has been reported to be comprised of several sibling members. Anopheles subpictus s.l. is widely distributed species prevalent throughout Oriental and Australasian Zones; mainly in Afghanistan, Australia, Bangladesh, Cambodia, China, India, Indonesia, Iran, Malaysia, Maldives, Mariana Islands, Myanmar (Burma), Nepal, New Guinea (Island)-Papua New Guinea, Pakistan, Philippines, Sri Lanka, Thailand 
and Vietnam [2]. In India, An. subpictus s.l. is the most common species occurring in all the mainland zones [3] and is found up to 1900 above msl and in many parts of Himalayas, though in small numbers. Anopheles subpictus s.l. gradually declines in abundance proceeding eastwards in India [4]. Other nominal taxa, An. sundaicus s.l., has been recorded mainly from the coastal areas of north-eastern India, Andaman \& Nicobar (A\&N) Islands, Peninsular Malaysia, Malaysian Borneo (Miri, Sarawak), northern Sumatra \& Java, and Indonesia [5]. Currently, the distribution of An. sundaicus s.l. in India is limited to the A\&N Islands and Kutch (western coast of India) [6-7]. Anopheles sundaicus s.l. has been reported to be disappeared from Chilka (Odisha, India) [8], which has been reported earlier [9].

In India, An. sundaicus s.l. is considered as a potent malaria vector, but An. subpictus s.l. has not been recognized yet as a malaria vector by the national malaria control programme [10]. However, An. subpictus s.l. is considered a potential vector in Southeast Asian countries $[11,12,13,14]$. In India, there are increasing evidences supporting the role of An. subpictus as a potential malaria vector, especially in coastal areas of India [15, 16] and Sri Lanka [17]. The varying vectorial potential in different geographical areas is most likely due to the presence of different biological species (cryptic species) present in An. subpictus s.l. In India, four sibling species of An subpictus, provisionally designated as species A, B, C and D have been recognized based on paracentric inversions present on the chromosome $X$ [18]. However, the status of sibling species in other countries, except Sri Lanka (where species A and B were identified based on chromosomal inversions) [19], remains obscure. Though An. subpictus s.l. has been incriminated as a malaria vector in several places in India, mostly in coastal areas, the differential role of their sibling species in malaria transmission is not well understood. Apparently, species B is an efficient vector of malaria, which is prevalent in coastal areas of India [19] and Sri Lanka [20]. Anopheles sundaicus s.l., comprises of four sibling species [5], designated as An. sundaicus s.s., An. epiroticus s.s. Linton \& Harbach (formerly, An. sundaicus species A) [21], An. sundaicus species D [22, 23] and An. sundaicus species E [24]. All of them act as predominant malaria vectors depending upon the location [25].

Morphologically, An. subpictus s.l. and An. sundaicus s.l. are almost similar and are distinguished based on the presence/absence of speckling on legs [26]. However, the taxonomic status of members of An. subpictus seems to be ambiguous based on the molecular phylogenetic studies which revealed that the majority of the morphologically attributed species B of An. subpictus is closely related to An. sundaicus complex and far distantly related to other members of An. subpictus s.l. [27-28]. Therefore, Surendran et al. (2010) [27] 
recognized species B of Subpictus Complex as a member of Sundaicus Complex. Interestingly, species B of Subpictus Complex [29] and members of the Sundaicus Complex are prevalent mainly in coastal areas and islands [14], although ecological plasticity in the breeding preference has also been noted [5].

Molecular characterization of An. subpictus from different geographical regions is important in identifying different biological forms, their distribution and role in malaria epidemiology. Studies carried out in Sri Lanka revealed the presence of two distinct molecular forms. Very recently, three additional molecular forms in respect of ITS2 has been reported from Thailand and Indonesia [30]. However, reliable published data on molecular forms of An. subpictus in Indian territory is not available. Few published and unpublished data from GenBank showed a high degree of polymorphism in ITS2 sequences, in the Indian population, to the extent that every individual was different [31-33], which raises suspicion in the quality of sequences. The verification of such data is warranted. Therefore, we attempted to characterize the rDNA of An. subpictus s.l. population from wide geographical areas in the Indian subcontinent in addition to closely related species An. sundaicus s.l.

For molecular characterization, we preferred nuclear ribosomal DNA (rDNA), particularly ITS2 and 28S rDNA, which have been extensively used in species identification due to their high uniformity in sequence in an interbreeding population, while differences exist between species [34]. Such uniformity of sequence in a species is believed to be due concerted evolution acting on rDNA, which tends to homogenize sequence [35]. The homogenization of rDNA is thought to be due to unequal crossing over of rDNA copies arranged in a tandem fashion, but the phenomenon has not been fully understood [36]. On the other hand mitochondrial DNA, COI in particular has also been successfully used in barcoding of life where sufficient gap, known as 'barcoding gap' (an arbitrary threshold), exists between intraspecific variation and interspecific divergence. In closely related species, such gap often doesn't exist, but a high percentage of well-differentiated species has similar or even identical COI sequences [37], particularly in dipteran [38]. Such overlap may be due to the retention of ancestral polymorphism and introgression [39]. Moreover, rDNA is thought to be advantageous over the mtDNA in terms of the speed of lineage sorting of its multicopy rDNA array [39].

\section{Methodology}




\section{Mosquito collection:}

Adult female An. subpictus s.l. and An. sundaicus s.l. mosquitoes were collected from different parts of the Indian subcontinent, mainly from mainland India, A\&N Islands (India) and Sri Lanka. From mainland India, mosquitoes were collected from Ranchi (Jharkhand, $\left.23^{\circ} 21^{\prime} \mathrm{N}, 8^{\circ} 18^{\prime} \mathrm{E}\right)$, Nuh (Haryana, $\left.28^{\circ} 06^{\prime} \mathrm{N}, 76^{\circ} 59^{\prime} \mathrm{E}\right)$, Goa (15³ $\left.38^{\prime} \mathrm{N}, 73^{\circ} 45^{\prime} \mathrm{E}\right)$, Alwar (Rajasthan, $27^{\circ} 37^{\prime} \mathrm{N}, 76^{\circ} 35^{\prime} \mathrm{E}$ ), Jodhpur (Rajasthan, $26^{\circ} 18^{\prime} \mathrm{N}, 73^{\circ} 00^{\prime} \mathrm{E}$ ), Gadchiroli (Maharashtra, $\left.20^{\circ} 10^{\prime} \mathrm{N}, 80^{\circ} 00^{\prime} \mathrm{E}\right)$, Delhi $\left(28^{\circ} 34^{\prime} \mathrm{N}, 77^{\circ} 01^{\prime} \mathrm{E}\right)$, villages surrounding Chilka lake (Odisha) and Puducherry. The villages surveyed surrounding Chilka lake, which is a large brackish water lagoon covering an area of over $1,100 \mathrm{~km}^{2}$ in Orrisa state, were Panasapada $\left(19^{\circ} 43^{\prime} \mathrm{N} 85^{\circ} 31^{\prime} \mathrm{E}\right)$, Satapada $\left(19^{\circ} 40^{\prime} \mathrm{N} 85^{\circ} 26^{\prime} \mathrm{E}\right)$, Brahmgiri $\left(19^{\circ} 47^{\prime} \mathrm{N} 85^{\circ} 36^{\prime} \mathrm{E}\right)$, Sipakuda $\left(19^{\circ} 23^{\prime} \mathrm{N} 85^{\circ} 04^{\prime} \mathrm{E}\right)$, Minsa $\left(19^{\circ} 18^{\prime} \mathrm{N} 84^{\circ} 47^{\prime} \mathrm{E}\right)$, Siara $\left(19^{\circ} 44^{\prime} \mathrm{N} 85^{\circ} 32^{\prime} \mathrm{E}\right)$ and Gambhari $\left(19^{\circ} 72^{\prime} \mathrm{N}, 85^{\circ} 46^{\prime} \mathrm{E}\right)$. In Puducherry, mosquitoes were collected from Kaliankuppam $\left(12^{\circ} 05^{\prime} \mathrm{N}\right.$ $\left.79^{\circ} 55^{\prime} \mathrm{E}\right)$, Munjalkuppam $\left(12^{\circ} 02 \mathrm{~N} 79^{\circ} 76^{\prime} \mathrm{E}\right)$, Sedarapet $\left(12^{\circ} 00^{\prime} \mathrm{N} 79^{\circ} 44^{\prime} \mathrm{E}\right)$, Pillayarkuppam $\left(11^{\circ} 48^{\prime} \mathrm{N} 79^{\circ} 46^{\prime} \mathrm{E}\right)$. From A\&N Islands, mosquitoes were collected from Kimios, Car Nicobar $\left(9^{\circ} 15^{\prime} \mathrm{N} 92^{\circ} 76^{\prime} \mathrm{E}\right)$ and Sippighat, Port Blair $\left(11^{\circ} 59^{\prime} \mathrm{N} 92^{\circ} 68^{\prime} \mathrm{E}\right)$. In Sri Lanka, mosquitoes were collected from Kallady $\left(7^{\circ} 42^{\prime} \mathrm{N} 81^{\circ} 42 \mathrm{E}\right)$, Muthoor $\left(8^{\circ} 27^{\prime} \mathrm{N} 81^{\circ} 16^{\prime} \mathrm{E}\right)$, and Chenkalady $\left(7^{\circ} 47\right.$ 'N 813' E). Few An. sundaicus s.l. mosquitoes collected from Thanbyuzayat Township, Mon State $\left(15^{\circ} 58^{\prime} \mathrm{N} 97^{\circ} 44^{\prime} \mathrm{E}\right)$ were also included in the study. The geographical location of mosquito collection sites is depicted in Figure 1. Mosquitoes were either preserved in isopropanol or kept dried in microcentrifuge containing a piece of silica gel crystal. Where feasible, live female mosquitoes were transported to the laboratory for oviposition and identification of sibling species based on the number of float-ridges on eggs. The adult female mosquitoes were identified morphologically using keys by Christophers (1933) [26] and Reid (1968) [40].

\section{Egg float-ridges count}

Live An. subpictus mosquitoes were transported from mainland India only. The transported mosquitoes from the field were allowed to feed overnight on a- rabbit. Eggs were obtained from individual morphologically identified gravid-females in a plastic bowl with the inner side lined with blotting paper and containing a small amount of water for keeping the blotting paper moist. The mosquitoes, which successfully laid their egg, were persevered in a microcentrifuge tube containing isopropanol for molecular studies. Eggs from individual mosquitoes were transferred on to microslides and the number of ridges on egg-floats obtained were counted under a transmission microscope using 10X objective lens. At least 10 
eggs from each mosquito were examined. Based on the mode number of ridges, the mosquitoes were classified for sibling species following Suguna et al. (1994) [18]

\section{DNA extraction, PCR amplification and sequencing}

DNA was extracted from individual mosquitoes following Coen et al. (1982) [41].

Two adjacent regions of rDNA, i.e., ITS2 and partial 28S rDNA (D2-to-D3 domains), were PCR-amplified separately following Singh et al. (2006) [42]. In addition, to obtain a continuous stretch of rDNA covering partial 5.8S, full ITS2 and partial 28S rDNA (up to d3 domain) an approximately $2 \mathrm{~kb}$ region was also amplified using primers ITS2A and D3B (Table 1) from at least two representative samples of each molecular form of An. subpictus s.l. and An. sundaicus s.l. and one sample of An. epiroticus,. The PCR conditions were as described by Singh et al. (2006) [42], except extension time, which was increased to 1.5 minutes. The PCR products were cleaned using Exo-Sap IT (Thermo-Scientific) and sequenced using Big Dye Terminator v3.1 (Thermo-Scientific). The products were cleaned using the vendor's protocol and electrophoresed in ABI-Prism 3770xl DNA sequencer. For the sequencing of ITS2 products, we used primers that were used for PCR amplification, i.e., ITS2A and ITS2B. Larger PCR products were sequenced using a primer walking strategy. The primers used for primer walking sequencing were ITS2A, ITS2B, D2A, D2B, D3A and D3B (sequences are provided in Table 1)

Five individuals of each molecular form, except An. epiroticus $(\mathrm{n}=1)$, were also sequenced for cytochrome oxidase II (COII) mitochondrial DNA. An approximately $750 \mathrm{bp}$ region of the COII gene was PCR-amplified in a $20 \mu \mathrm{L}$ reaction mixture using GOTaq Master Mix (Promega), $0.5 \mu \mathrm{M}$ of each primer COIIF and COIIR (Table 1) and $0.5 \mu \mathrm{L}$ of DNA. The PCR thermal cycling conditions were $95^{\circ} \mathrm{C}$ for 2 min followed by 35 cycles each at $95^{\circ} \mathrm{C}$ for $30 \mathrm{~s}, 55^{\circ} \mathrm{C}$ for $30 \mathrm{~s}, 72^{\circ} \mathrm{C}$ for $1 \mathrm{~min}$ and a final extension at $72^{\circ} \mathrm{C}$ for $7 \mathrm{~min}$. The PCR products were cleaned using Exo-Sap IT (Thermo Scientific) and sequenced using Big Dye Terminator v3.1 (Thermo Scientific)..

\section{Cloning, sequencing and phasing of haplotypes}

During the sequencing of ITS2 of a molecular form of An. subpictus s.l. (Form A) collected from mainland India and Sri Lanka, we noticed the presence of mixed bases in DNA sequence chromatogram starting from a specific point due to the presence of indel in one of the two haplotypes present in the mosquito (Figure 2). To phase out the sequence of two haplotypes, PCR product amplified for the ITS2 region of a total of five samples (three samples from 
mainland India, one each from Delhi, Ranchi and Kutch, and two samples from Sri Lanka) were sequenced after cloning. For cloning, briefly, PCR products were purified using Qiaquick PCR Purification Kit, cloned in pGEM-T Vector System (Promega) following vendor's protocol and transformed into chemically competent $E$. coli $\mathrm{DH} 5 \alpha$. The transformants were plated on LB-Agar containing $100 \mu \mathrm{g} / \mathrm{ml}$ ampicillin. White colonies were picked up and plasmid DNA was isolated by boiling them in $50 \mu \mathrm{l}$ of TE buffer. At least five clones from each mosquito were sequenced using universal primers T7 and SP6 (sequences provided in Table 1).

\section{Sequence analyses and phylogenetic inferences}

The DNA sequence chromatograms were edited using Finch TV (Geospiza, Inc.) and aligned using an online tool ClustalW 1.4 [43] available at https://www.genome.jp/tools-bin/clustalw. Since An. subpictus Form A had two haplotypes with 12 bp indel in ITS2, and sequence chromatograms were ambiguous from the point of indel, identification of two haplotypes were done on the basis of combining reads from forward sequences and reverse sequence (1X) up to the point of start of indel. The determination of sequence in the indel region was made empirically, as illustrated in Figure 2.

Phylogenetic analyses of ITS2 and 28S-D2-D3 were performed individually using software PAUP* version 4.0 beta 10 [44] . For phylogenetic analysis of ITS2, sequences of four An. sundaicus s.l. variants, i.e., An. epiroticus s.s. (variant I, GenBank accession no. AY768540), variant II (AY768541), An. sundaicus cytotype D. (variant III, AY768542), An. sundaicus s.s. (variant IV, AY768543) [24], An. indefinitus (GQ870332) and sequences of An subpictus variants from Thailand (MT068425 and MT068434) and Indonesia (MT068436) [30] were also used. Sequences of An. fluviatilis (DQ345964) [42] and An. gambiae (JN994138) were taken as outgroup taxa for ITS2 and An. gambiae (KC177663) and An. fluvialitis (DQ665846) [42] were taken as outgroup taxa for 28S-D2-D3 phylogenetic analysis. Anopheles gambiae was chosen as outgroup due to its phylogenetic proximity with An. subpictus and An. sundaicus complexes, whereas An. fluviatilis (belongs to Myzomyia series of subgenus Cellia) was chosen as it is phylogenetically relatively distant from An. subpictus and An. sundaicus complexes. We did not include ITS2 sequences of the Indian and Sri Lankan An. subpictus (published or submitted in GenBank) in the analysis due to significant error in the sequences (to the extent that every individual was different $[31,32,33]$ ), resulting from quality issues mostly arising due to the presence of indel in one of the two 
haplotypes present in molecular Form A, which is prevalent throughout mainland India and Sri Lanka. Maximum Likelihood (ML) methods were used for the construction of phylogenetic trees. The ML analyses were carried out using the heuristic searches and TBR branch-swapping algorithm with ten random taxon addition sequences. For ML-tree construction, the best evolutionary model of nucleotide substitution that fits the data were obtained using software Modeltest 3.7 [45]. The robustness of inference was calculated by the bootstrap method (1000 times) within PAUP. The estimated bootstrap values were reported as Maximum Likelihood bootstrap percentages (MLB).

\section{Allele-specific PCR (ASPCR) for the identification of molecular forms of An. subpictus in mainland India}

Since the sequencing of a large number of samples was not feasible, we developed a PCR assay for the quick identification of two molecular forms, An. subpictus Form A and Form B, only forms prevalent in mainland India. A universal primer Sub F (5'-ACT GCA GGA CAC ATG AAC ACC G-3') was designed from upstream of ITS2A sequence and two reverse primers namely SUBP-A (5'-CGT TAC ACG CAA CAA GCG AC-3') and SPB (5'-GCC GAC ACC ACC AAC TG-3'), specific to Form A and B of An. subpictus, respectively, were designed. The expected amplicon sizes for Form A and B of An. subpictus are 563 and 444 bp, respectively. The PCR reaction (15 $\mu 1)$ was carried out using GOTaq Master Mix (Promega) and $0.2 \mu \mathrm{M}$ of each primer. The PCR thermal cycling conditions were $95^{\circ} \mathrm{C}$ for 2 min, followed by 35 cycles each at $95^{\circ} \mathrm{C}$ for $30 \mathrm{~s}, 58^{\circ} \mathrm{C}$ for $30 \mathrm{~s}, 72^{\circ} \mathrm{C}$ for $45 \mathrm{~s}$, and a final extension at $72^{\circ} \mathrm{C}$ for $7 \mathrm{~min}$. The PCR products were visualized on $2 \%$ agarose gel containing ethidium bromide under the gel documentation system. Numbers of samples on which ASPCR was performed have been given in Table 2.

\section{Results}

\section{DNA sequences analyses}

Details of samples sequenced for 28S-D2-D3 and ITS2 are provided in

Table 2. Analysis of sequences revealed a total of five distinct molecular forms (in respect to ITS2 and 28S rDNA combined), of which three forms were from morphologically identified An. subpictus s.l. and two from An. sundaicus s.l. Sequences obtained from representative samples of each molecular forms (and haplotypes) after amplifying complete stretch of partial 5.8S rRNA, complete ITS2 and partial 28S rRNA (D1-D3 domain) have been shown in the aligned form in Figure S1. The sequences are also available from GenBank (accessions 
numbers: MW078484 to MW078490). The three forms of An. subpictus have been designated as molecular forms A, B and C. Form A of An. subpictus s.l. were recorded from mainland India and Sri Lanka, form B was found restricted to the coastal areas of mainland India (Chilka, Goa, Puducherry) and Sri Lanka island while form C from A\&N Islands (Port Blair and Car Nicobar). The two molecular forms of An. sundaicus s.l were identified as An. epiroticus s.s. and An. sundaicus species D based on homology with published ITS2 sequences $[21,23,24]$. The characterization of species was done based on the polymorphism at three nucleotide positions of ITS2, i.e., 479 (T/C), $538(\mathrm{G} / \mathrm{T})$ and 603 (C/indel) (nucleotide position as described by Linton et al.(2005) [21]). Nucleotide bases at these three sites for $A n$. epiroticus, An. sundaicus D and An. sundaicus s.s. were TGC, CGC and CT- (dash denotes indel), respectively. The An. epiroticus s.s was recorded from Myanmar and Car Nicobar (A\&N Island) and An. sundaicus species D from Port Blair and Car Nicobar (A\&N Island). The sequence of An. epiroticus s.s. recorded from Myanmar and A\&N Islands had 100\% homology to An. epiroticus s.s. [21] (variant I [24]). However, An. epiroticus from Car Nicobar was had mixed nucleotide bases $(\mathrm{G}+\mathrm{T})$ at the nucleotide position 538 (nucleotide position as per Linton et al.(2005)[21], where 'G' peak was substantially prominent as compared to 'T' (Figure 3). The An. epiroticus from Car Nicobar was identical to haplotype 'TK' designated by Zarowiecki et al. (2014) [58]. The ITS2 of An. sundaicus D was identical to variant III [24]. However, there was no difference in the 28S-D1-D3 sequence between An. epiroticus and An. sundaicus D. No individual variation in nucleotide sequences was found in each molecular form in a specific population.

\section{Intragenomic sequence variation in An. subpictus molecular Form A}

DNA sequencing of ITS2 of An. subpictus (Form A) resulted in mixed nucleotide peaks from a specific position of nucleotide sequence (from base position 450 in Figure S1) resulting in an ambiguous sequence (Figure 2) from this point due to the presence of mixed haplotypes where one haplotype had indel. Phasing of haplotypes through sequencing of cloned PCR product revealed the presence of two haplotypes (referred to as haplotype 1 and haplotype 2 in Figure S1), which differ by indel/insert of 12 . The presence of these two haplotypes was found fixed in Form A throughout its distribution from northern India to Sri Lanka.

\section{Genetic distance and phylogenetic analyses}

The genetic distances and number of nucleotide substitutions, considering ITS2 and 28S-D2D3 sequences, between three molecular forms of An. subpictus (A, B and C), An. epiroticus and An. sundaicus D are shown in Table 3. It was observed that An. subpictus Form A is 
distantly related to all other molecular forms of An. subpictus s.l. and An. sundaicus s.l. with nucleotide substitutions 100 to 106 and genetic distances 0.063 to 0.066 (Kimura-2parameter). However, two molecular forms of An. subpictus, i.e., Form B and C, An. epiroticus and An. sundaicus species D are closely related (nucleotide substitution 1 to 10; Kimura-2-parameter genetic distance 0.001 to 0.006 ).

Recently two new molecular forms of An. subpictus s.l. have been reported from Thailand and Indonesia with respect to ITS2 [30]. Therefore, a separate genetic distance analysis was performed, after including molecular forms reported from Thailand and Indonesia (representative GenBank sequences MT068425 and MT068436) [30] and An. indefinitus (GQ870332). The genetic distance and number of nucleotide substitutions are displayed in Table 4. It was observed that there is no genetic distance between Form C (India) and MT068436 (Indonesia) Table 4, but these sequences differed by 2 bp indel (Figure S1). Anopheles subpictus Forms B, C, molecular forms from Thailand and Indonesia (MT068425, MT068434, MT068436), An. epiroticus s.s., An. sundaicus species D and An. indefinitus are closely related (nucleotide substitution 0 to 10; Kimura-2-parameter genetic distance 0.0 to 0.018 ) and are distantly related to Form A (nucleotide substitution 48 to 52; Kimura-2-parameter genetic distance 0.094 to 0.105 ).

The phylogenetic analysis of all molecular forms of An. subpictus and An. sundaicus s.l. from the Indian subcontinent alongwith four variants in An. sundaicus s.l., An. indefinitus and An. subpictus s.l. variants from Thailand and Indonesia were performed using ITS2 sequences. The best-fit model inferred for ITS2 sequences with outgroup taxa TPM2uf $+\mathrm{G}$ was taken for maximum likelihood (ML) analysis. Construction of phylogenetic tree resulted in two distinct monophyletic clades supported by high bootstrap value (100), i.e., subpictus clade comprising of the single molecular form of An. subpictus (Form A) and sundaicus clade comprising of An. subpictus Form B, An. subpictus Form C, molecular forms of An. subpictus from Thailand and Indonesia, all variants of An. sundaicus s.l. and An. indefinitus (Figure 4).

Phylogenetic tree was also constructed for 28S rDNA (D2-D3) sequences of all molecular forms of An. subpictus (Forms A, B and C), An. sundaicus D and An. epiroticus s.s. prevalent in the Indian subcontinent. The best-fit model of nucleotide substitution TIM $3+\mathrm{G}$ was implemented in the construction of ML trees. Cladogram derived from 28S rDNA 
sequences also resulted in the generation of two distinct monophyletic clades similar to ITS2, supported with high bootstrap value (100) (Figure 5).

Analysis of limited numbers of COII sequences of all representative molecular forms based on rDNA sequences revealed the presence of multiple haplotypes in each form. We recorded 3/5 (number of haplotypes/number sequenced) haplotypes in An. subpictus Form A, 3/5 in Form B, 1/5 in Form C, 2/5 in An. sundaicus D and 1/1 in An. epiroticus. The Maximum Likelihood phylogeny estimate based on COII data for all molecular forms of Indian An. subpictus and An. sundaicus complex was constructed using software PAUP 4.0 beta. The best fit model used was GTR $+\mathrm{I}+\mathrm{G}$, as estimated by the Modeltest 3.7 [45] (Figure 6). ML bootstrap values based on 1000 replicates were calculated. ML tree generated two distinct monophyletic clades similar to the phylogenetic tree based on rDNA. Based on COII phylogeny, An. subpictus form $\mathrm{C}$ was much closer to An. epiroticus than any members of $A n$. subpictus.

\section{Allele-specific PCR:}

Though this PCR was developed with an intension to differentiate the two forms of morphologically identified An. subpictus s.l. (An. subpictus Form A and Form B) in the Indian mainland and Sri Lanka, but upon discovery of additional species under the sundaicus clade (i.e., An. subpictus Form C) from A\&N Islands, we found that this PCR cannot differentiate An. subpictus Form B from An. subpictus Form C. However, this PCR can discriminate members of subpictus clade (An. subpictus A) and sundaicus clade (An. subpictus Form B, C, An. sundaicus D and An. epiroticus) (Figure 7). This PCR was therefore used to differentiate molecular forms A and B of An. subpictus s.l. in areas where Form C or An. sundaicus s.l. was absent (mainland India and Sri Lanka).

\section{Distribution of different molecular forms of An. subpictus s.l. and An. sundaicus s.l.}

The distribution of different molecular forms of An. subpictus s.l. and An. sundaicus s.l in different localities as determined by DNA sequencing as well as by AS-PCR has been shown in Table 2 and Figure 1. It was observed that An. subpictus Form A is prevalent throughout mainland India (found exclusively in inland areas) and Sri Lanka, whereas Form B was prevalent only in coastal areas or A\&N islands. Anopheles subpictus Form C is prevalent only in the A\&N Islands. Anopheles sundaicus D and An. epiroticus were found in Car Nicobar of A\&N Islands. 


\section{Assignment of sibling species based on the mode number of float-ridges on eggs}

The designation of sibling species of An. subpictus collected from mainland India was assigned based on the mode number of ridges on their egg's float following Suguna et al. (1994) [18]. The distribution of sibling species based on the number of ridges and their molecular forms have been provided in Table 5. It was observed that all individuals $(n=51)$ belonging to molecular Form B were correctly assigned to species B based on the mode number of float-ridges. All molecular Form A $(n=97)$ which were identified as species A, C or $\mathrm{D}$ based on the mode number of float-ridges, of which majority $(80 \%)$ fall under the species C category (Figure 8). The mode number of float-ridges on eggs for form B ranged between 15 and 19, and for Form A between 22 and 33 (Figure 9a). The number of floatridges on individual eggs for Form B ranged between 14 and 20, and for Form A ranged between 21 and 35 (Figure 9b).

The frequency distribution of mode number of float-ridges from individual mosquito progeny and number of float-ridges counts from individual egg (pooled data) for molecular Form A and B are shown in Figure 9a and b respectively. The figures clearly depict two independent curves, each showing normal distribution, one corresponding to molecular Form B (species B) and another for Form A (comprising of species A, C and D). Based on the distribution pattern of the number of floats-ridges that correlate with molecular forms, it is suspected that species A, C and D might be conspecific while species B is a distinct species.

\section{Seasonal prevalence of An. subpictus Form A and B in areas surrounding brackish water lagoon and near coastal area}

A survey was carried out in areas surrounding Chilka lake (a brackish water lagoon) and Puducherry (a coastal area) in monsoon and post-monsoon season, to know the relative prevalence of An. subpictus Form A and B in monsoon and post-monsoon season. In the Chilka lake area, only An. subpictus Form B was found in the dry season (post-monsoon) when there is no freshwater breeding source available except a large brackish water lagoon. In the monsoon season, when fresh water breeding habitat is prevalent beside brackish water lagoon, Form A was also present (4.7 to 7.6\%) alongside Form B. In another area, Puducherry (a coastal area), the proportion of species B was much higher in post-monsoon as compared to autumn. The relative proportion of An. subpictus Form A and B in the area surrounding Chilka Lake and coastal area of Puducherry in monsoon and post-monsoon season has given in Table 6. The data indicate that the prevalence of Form A of An. subpictus determined by the availability of freshwater breeding sources. 


\section{Discussion}

Correct identification of anophelines and their sibling species is crucial for the success of any malaria control programme because of possible inherent variations in the epidemiologicallyimportant biological characteristics among sibling species, e.g., vectorial competence [46-47], insecticide resistance [48-51] and host preference [52-53]. In India, An. sundaicus is considered as an efficient malaria vector whereas An.subpictus s.l. has not been recognized so far as a malaria vector by the national malaria control programme [10]. However, published evidences suggest that at least coastal form of An. subpictus is a malaria vector $[15,16]$. On the other hand, An. subpictus is considered as an important malaria vector in coastal Malaysia [14] and Indonesia [12, 13]. These geographically isolated populations differ in breeding preference, where the Malayan population prefers to breed in brackish water, unlike the majority of Indian An. subpictus populations that prefer to breeds in freshwater [14]. In view of the presence of such difference in biological characteristics, recognition of sibling species or 'fixed' molecular forms in geographically widely distributed An. subpictus s.l. population is an important consideration in understanding their relative epidemiological significance.

So far, four sibling species have been described from a south Indian population of $A n$. subpictus s.l. (provisionally designated as species A, B, C and D) based on the arrangement of inversions present on two loci on the polytene chromosome $\mathrm{X}$ [18]. To the best of our knowledge, this technique has not been effectively used for the identification of sibling species in An. subpictus s.l., except in a neighbouring country, Sri Lanka [20], where inversions on a single locus $\left(\mathrm{X}^{+\mathrm{a}}\right.$ and $\left.\mathrm{X}^{\mathrm{a}}\right)$, out of two diagnostic loci $\left(\mathrm{X}^{\mathrm{a} / \mathrm{a}}\right.$ and $\left.\mathrm{X}^{\mathrm{b} /+\mathrm{b}}\right)$, were examined (which preclude the identification of species $C$ and D). Identification of sibling species in malaria control programme is challenging due to the non-availability of simpler technique, as an alternative to the cytological technique that requires a highly specialized skilled personnel to read banding patterns. Moreover, the cytological technique can be applied only on a fraction of a population, i.e., only live semi-gravid female mosquitoes. As an alternative, molecular tools can be used for the identification of sibling species which are easier and can be applied to dead or alive mosquitoes of either sex. Identification of 'fixed' molecular form of rDNA, particularly in ITS2, is a primary step toward the recognition of sibling species. In this direction, ITS2 of An. subpictus s.l. populations have been characterized in Sri Lankan [27], Thai and Indonesian population [30], however, reliable data on molecular forms from India is lacking. The present study is an attempt to characterize all 
the molecular forms of morphologically identified An. subpictus s.l. and An. sundaicus s.l. prevalent in the Indian subcontinent to uncover hidden cryptic species, distribution pattern and to establish their phylogenetic relationship. Characterization of molecular forms will help in identifying sibling species and developing a reliable and simpler method for their identification. Characterization of An. sundaicus s.l. was included in this study in view of the report of incongruence in molecular taxonomy with formal (morphological) taxonomy, where one molecular form of An. subpictus s.l. (mostly species B) was found to be a close relative of An. sundaicus s.l [27]. As a result, Surendran et al. (2010) [27] recognized them as a member of the Sundaicus Complex. Earlier phylogenetic study on Sri Lankan An. subpictus [27, 28] was based on partial ITS2 and D3 domain of 28S rDNA. Here we used full length ITS2 sequence and 28S-D1-D3 to identify molecular forms of both An. subpictus s.l. and An. sundaicus s.l. from the Indian subcontinent.

This study revealed the presence of a total of five molecular forms in SundaicusSubpictus complex in the Indian subcontinent (both by ITS2 as well as 28S-D1-D3): three molecular forms present in morphologically identified An. subpictus (Form A, B and C) and two molecular forms in An. sundaicus complex (An. epiroticus and An. sundaicus D). Phylogenetic analysis using two regions of rDNA revealed two distinct clades where An. subpictus Form B and C, An. epiroticus, An. sundaicus and An. indefinitus falls under one clade (Sundaicus) and one molecular form, Form A, falls under distantly related clade (Subpictus). Thus, the phylogenetic relationship showed incongruence with the morphological delimitation of the species. In an earlier study, Surendran et al. (2010) [27] showed that most of the An. subpictus species B (Form B in our study) from Sri Lanka fall under Sundaicus complex and therefore considered as a member of Sundaicus Complex. We include another molecular form of An. subpictus, i.e., Form C, found in A\&N Island as a member of Sundaicus Complex. The two molecular forms very recently reported from Indonesia and Thailand [30] also fall in the same clade and closely related to Indian molecular forms Form $\mathrm{B}$ and $\mathrm{C}$.

The designation of molecular forms in this study is based on ribosomal DNA (ITS2 and 28SrDNA), where we didn't find any intraspecific variation in a specific population (due to concerted evolution), as seen in mitochondrial DNA (maternally inherited and mutations are passed through generations). The absence of individual variation in DNA sequences in molecular forms of An. subpictus across wide geographical areas is contrary to the findings by Kaura et al. (2010) [31], Chattopadhyay et al. (2013) [32] and Chhilar et al. [33], where they 
recorded individual variation in ITS2 sequences in samples collected from inland India. These sequences are very similar to Form A and we believe that individual differences in ITS2 sequences presented in above-mentioned publications is due to errors in the sequence-read of Form A arising due to the $12 \mathrm{bp}$ indel in one haplotype leading to ambiguous sequence beyond the point of indel in sequence read. Interestingly, the intragenomic variation in Form A, with the presence of two haplotypes, was found fixed throughout its distribution, from north India to Sri Lanka. The fixed molecular forms based on rDNA, which are found in sympatricity, deserve distinct specific status, but the specific status of closely related molecular forms, which are allopatric, is obscure. Thus the two molecular forms A and B found in sympatry in southern Asia (India and Sri Lanka) are genetically isolated but the specific status of other molecular forms found in South-east Asia (A\&N Islands, Thailand and Indonesia) is not absolute. Among Sundaicus Complex, An. sundaicus D and An. epiroticus have been found sympatric in this study in Car Nicobar Island, and they may be considered distinct biological species.

Wilai et al. [30] reported that An. subpictus s.l. from Thailand and Indonesia are different from India and Sri Lanka. They recorded two types of ITS2 sequences from Thailand which were identical except in one type of sequence. There was a mixed nucleotide base at one position. It is unlikely that these two forms are reproductively isolated. The specific status of allopatric molecular forms cannot be ascertained using population genetic analysis, which can be verified using crossing experiments only. Recently, Wilai et al. [30] has carried out crossing experiments in two forms having different mtDNA sequence (but same molecular forms with respect to ITS2) and found genetic compatibility between them. We consider these two mtDNA forms as intraspecific variation because such variation is common in mtDNA being inherited maternally. Such intraspecific variation were also found in this study where we recorded multiple sequence of COII mtDNA, even in small numbers of samples. The molecular forms reported from Thailand and Indonesia were very close to Indian molecular forms $\mathrm{B}$ and $\mathrm{C}$ with a very low genetic distance ranging from 0.0 to 0.018 (with respect to ITS2). The lack of genetic distance between Indonesian An. subpictus and Form C was due to $100 \%$ similarity in sequences except presence of two bp indel in Form C.

Interestingly two molecular forms of An. subpictus s.l., Form B and C, which falls under sundaicus clade, are found in coastal areas or islands. This may be due to their breeding preference is brackish water, similar to most of the members of An. sundaicus complex. This is complemented by the fact that, in Chilka Lake (a brackish lagoon), we found exclusively 
Form B in Post monsoon season (October and February), while this was present along with Form A in Monsoon season (August-September) when freshwater breeding habitats are abundantly present beside brackish water habitat. Suguna (1982) [29] and Panicker et al. (1981) [15] also found species B of Subpictus Complex along with species A in the rainy season. These observations indicate that Form B and Form C of An. subpictus, found in coastal areas or islands, has a preference to breed in brackish water. Another form of $A n$. subpictus, Form A, which is widely distributed throughout inland India, appears to breed in freshwater.

Review of literature shows that species B of An. subpictus, found mainly in coastal areas $[19,20]$, is a potential malaria vector $[15,54]$. Recently An. subpictus s.l. was reported be a potential malaria vector from Goa (coastal area) [16]. This study confirms presence of molecular form B in Goa, It appears that molecular Form B (species B) is playing role in malaria transmission, however, further study is warranted. However, in some inland areas, An. subpictus has been found to have sporozoite in their salivary glands $[54,55,56]$. The differential role of these molecular forms in malaria transmission need to be confirmed.

We attempted to classify sibling species of Form A and B of the Subpictus Complex, prevalent in mainland India based on the mode number of float-ridges. All the molecular Form B were correctly classified as species B while the majority of Form A were characterized as species $\mathrm{C}$. Frequency distribution pattern of float-ridges clearly shows two distinct peaks, one peak corresponds to molecular Form A and another peak corresponds to Form B. It appears that all molecular Form A is a single species. Because majority of species $\mathrm{C}$ identified based on ridges on egg-floats belong to molecular Form A, it is erroneous to assign them as 'Species A' $[27,57]$. It is recommended that they may be described as molecular Form A instead of Species A. However, molecular Form B may be designated as 'Species B'. It is evident from our data that molecular method as well as mode number of float ridges can correctly identify species B, and can differentiate them from molecular Form A. However, morphological identification based on egg's ridges has certain limitations. It cannot differentiate species B from An. sundaicus s.l. due to overlapping range of ridges (range 16 to 20). Moreover, morphological identification based on the number of ridges is a cumbersome process and can be used with only live and gravid female mosquitoes, whereas molecular method can be applied on dead or alive mosquitoes irrespective of life stages and sex.

Anopheles sundaicus s.l. is widely distributed species and a malaria vector in the 
coastal region of Southeast Asia [25]. In India, this is the most prevalent and important malaria vector in the A\&N Islands. Earlier studies by Nanda et al. (2004) [22] and Alam et al. (2005) [23] revealed the presence of only one sibling species in A\&N Islands, i.e., An. sundaicus D (variant III). This study confirms the presence of An. sundaicus D in A\&N islands (Port Blair and Car Nicobar). We also recorded the presence of An. epiroticus in Car Nicobar island for the first time, though just one specimen out of small sample size $(n=52)$. Further studies are required to explore the presence of this species or new cryptic species in this area. In addition, we recorded the presence of An. epiroticus in Myanmar, which is in agreement with Dusfour et al. (2007) [24]. However, An. epiroticus recorded from Car Nicobar island was having mixed haplotypes of ITS2, unlike An. epiroticus from Myanmar or classic An. epiroticus. A similar variant has been reported in Indonesia, Thailand and Vietnam [58, 59]. Dusfour et al. (2007) [24] reported combinations of variants I and III, II and III, and I, II and III in continental Southeast Asia. Syafruddin et al. (2020) [59] hypothesized that such mixed bases may be due to possible hybridization/introgression between sympatric sibling species.

In this study, a new PCR based assay was developed for the differentiation of members of sundaicus and subpictus clade. Initially, it was designed to differentiate Form A and B of Subpictus Complex but, later upon discovery of Form C, we found that this could not differentiate Form B and C. However, this PCR can differentiate unambiguously members of Sundaicus (An. subpictus Form A) and subpictus clade (An. subpictus Form B, Form C and An. sundaicus s.l.). A similar ASPCR assay was developed by Surendran et al. (2013) [28], but we developed a new assay because we noticed that this ASPCR has cross-reactivity with other Indian malaria vector An. stephensi, which has superficial resemblance with An. sundaicus s.l. [26] and often misidentified in old specimens with lost palpal ornamentation and scales.

This study has certain limitation. As we do not have data on inversion genotypes of the polytene chromosome of An. subpictus s.l., we could not correlate association of molecular forms with previously designated sibling species. Recently one new species $A n$. pseudosundaicus belonging to the Pyretophorus series [60] has been designated from Kerala, southwest India, which unlike An. sundaicus s.l. doesn't have speckling on legs and closer to An. subpictus based on the DNA sequence of cytochrome oxidase C subunit 1. However, access to this molecular data has not been made public. Therefore, it could not be ascertained if this species is one of the molecular forms we described in this study. A more elaborate 
study on molecular characterization of all cytological forms of An. subpictus is desirable.

\section{Conclusions:}

Based on nuclear rDNA sequences, we identified three fixed molecular forms (Form A, B and C) in the morphologically classified An. subpictus s.l. and two forms in An. sundaicus s.l. in the Indian subcontinent. Molecular phylogenetic analysis revealed two diverse clades of mosquitoes where two molecular forms (B and C) of morphologically identified An. subpictus found mainly in coastal areas or islands along with molecular forms reported from Thailand and Indonesia were found to be close relative of An. sundaicus s.l. A molecular form of An. subpictus, Form A, prevalent in mainland India and Sri Lanka, has fixed intragenomic sequence variation in ITS2 throughout its distribution with the presence of two haplotypes differing by $12 \mathrm{bp}$ indel. The presence of An. epiroticus was recorded first time in Car Nicobar (A\&N Islands, India).

\section{Additional files}

Additional file 1: Figure S1 Alignment of rDNA sequences (ITS2 to D3 domain of 28S) of different molecular forms of An. subpictus s.l., and An. sundaicus complex s.l..

\section{Abbreviations}

A\&N: Andaman \& Nicobar

ASPCR

bp: base pair

COI: cytochrome oxidase I

COII: cytochrome oxidase II

ITS2: Internal Transcribed Spacer-2

min: minute

PCR: Polymerase Chain Reaction

rDNA: ribosomal DNA

s: second

TE: Tris-EDTA

\section{Acknowledgements}

Authors are thankful to Dr U Pe Htun, Medical Entomology Research Division, Yangon, 
Myanmar for providing An. sundaicus s.l. samples. Thanks are due to Mr Uday Prakash, Mr NS Bhakuni and Mrs Alka Kapoor for processing of samples and performing PCR reactions;

Mr Kanwar Singh, Mr Bhupal Ram, Mr Sadruddin for sample collections.

\section{Ethics approval and consent to participate}

Not applicable.

\section{Consent for publication}

Not applicable.

\section{Availability of data and materials}

All data generated or analyzed during this study are included in this published article and its additional files.

\section{Competing interests}

The authors declare that they have no competing interests.

\section{Funding}

Financial support to this study was provided by the Department of Science and Technology (DST), Government of India, under Women Scientist Scheme-B (Grant no. SR/WOS-

B/698/2016).

\section{Authors' contributions}

OPS conceived and designed study, designed PCR and sequencing strategies; AS performed PCR, DNA sequencing, phylogenetic analysis; GS performed cloning experiments; MKD and SNS supervised mosquito sampling from field and provided critical suggestions to the manuscript; BRK and HPL supervised the study and contributed to the manuscript. OPS and AS wrote the first draft of the manuscript and all authors provided critical input to the manuscript and approved the final manuscript

\section{Author details}

${ }^{1}$ National Institute of Malaria Research, Sector 8, Dwarka, Delhi-110077, India. ${ }^{2}$ National Institute of Malaria Research, Field Unit, Itki, Ranchi-835301, India. ${ }^{3}$ Department of Zoology, University of Jaffna, Jaffna 40000, Sri Lanka. ${ }^{4}$ Department of Zoology, Kumaun University, Nainital, India 


\section{References}

1. Harbach RE. The classification of genus Anopheles (Diptera: Culicidae): a working hypothesis of phylogenetic relationships. Bull Entomol Res. 2004;94:537-53.

2. Grassi GB. Artcora sulla malaria. Rendiconti dell' Accademia Lincei, 1899;8:559-61.

3. Chandra G, Bhattacharjee I, Chatterjee S. A review on Anopheles subpictus Grassi, a biological vector. Acta Trop. 2010;115:142-54.

4. Rao TR. The Anophelines of India (revised edition). Malaria Research Centre (Indian Council of Medical Research), Delhi. 1984;596 pp.

5. Sinka ME, Bangs MJ, Manguin S, Chareonviriyaphap T, Patil AP, Temperley WH, et al. The dominant Anopheles vectors of human malaria in the Asia-Pacific region: occurrence data, distribution maps and bionomic précis. Parasit Vectors. 2011;4:8.

6. Dash AP, Adak T, Raghavendra K, Singh OP. The biology and control of malaria vectors in India. Curr Sci. 2007;92:1571-8.

7. Singh N, Nagpal BN, Sharma VP. Mosquitoes of Kutch, Gujarat. Indian J Malariol. 1985;22:17-20.

8. Dash AP, Hazra RK, Mahapatra N, Tripathy HK. Disappearance of malaria vector Anopheles sundaicus from Chilika Lake area of Orissa State in India. Med Vet Entomol. 2000;14:445-9.

9. Iyengar MOT. The distribution of Anopheles ludlowii in Bengal and its importance in malaria epidemiology. Ind. J. Med. Res. 1931;19:499-524.

10. National Vector Borne Disease Control Programme. Operational manual for integrated vector management in India. 2016, 99 pp.

(https://nvbdcp.gov.in/WriteReadData/1892s/IVM10_March_2016.pdf) accessed 2 Oct 2020

11. Collins RT, Jung RK, Anoez H, Sutrisno RH, Putut D. A study of the coastal Malaria vectors, Anopheles sundaicus (Rodenwaldt) and Anopheles subpictus Grassi, in South Sulawesi, Sulawesi, Indonesia. 1979; World Health Organization, Geneva.

12. Cooper RD, Edstein MD, Frances SP, Beebe NW. Malaria vectors of Timor-Leste. Malar J. 2010;9:40.

13. Ndoen E, Wild C, Dale P, Sipe N, Dale, M. Relationships between anopheline mosquitoes and topography in West Timor and Java, Indonesia. Malar J. 2010;9:242.

14. Reid JA: A note on Anopheles subpictus Grassi and A. indefinitus Ludlow (Diptera: Culicidae). J Med Entomol 1966,3:327-331.

15. Panicker KN, Bai MG, Rao USB, Viswam K, Suryanarayanamurthy U. Anophelus 
subpictus, vector of malaria in coastal village of South-East India. Curr Sci. 1981;50:6945.

16. Kumar A, Hosmani R, Jadhav S, Sousa TD, Mohanty A, Naik M, et al. Anopheles subpictus carry human malaria parasites in an urban area of Western India and may facilitate perennial malaria transmission. Malar J. 2016;15:124.

17. Amerasinghe PH, Amerasinghe FP, Wirtz RA, Indrajith NG, Somapala W, Pereira LR, Rathnayake AMC. Malaria transmission by Anopheles subpictus Grassi in a new irrigation project in Sri Lanka. J Med Entomol. 1992;29:577-81.

18. Suguna SG, Rathinam GK, Rajavel AR, Dhanda V. Morphological and chromosomal description of new species in the Anopheles subpictus complex. Med Vet Entomol. 1994;8:88 - 94.

19. Reuben R, Kalyanasundaram M, Suguna SG. Salinity tolerance of sibling species in the taxon Anopheles subpictus Grassi 1899. Indian J Med Res. 1984;80:67-70.

20. Abhayawardana TA, Wijesuriya SR, Dilrukshi RR: Anopheles subpictus complex: distribution of sibling species in Sri Lanka. Indian J Malariol.1996;33:53-60.

21. Linton YM, Dusfour I, Howard TM, Ruiz La F, Manh ND, Dinh TH, Sochanta T, Coosemans M, Harbach RE. Anopheles (Cellia) epiroticus (Diptera: Culicidae), a new malaria vector species in the Southeast Asian Sundaicus Complex. Bull Entomol Res. 2005;95:329-39.

22. Nanda N, Das MK, Wattal S, Adak T, Subbarao SK. Cytogenetic characterization of Anopheles sundaicus (Diptera: Culicidae) population from Car Nicobar Island, India. Ann Entomol Soc Am. 2004;97:171-6.

23. Alam MT, Das MK, Ansari MA, Sharma YD. Molecular identification of Anopheles (Cellia) sundaicus from the Andaman and Nicobar Islands of India. Acta Trop. 2005;97:10-18.

24. Dusfour I, Michaux JR, Harbach RE, Manguin S. Speciation and phylogeography of the Southeast Asian Anopheles sundaicus complex. Infect Genet Evol. 2007;7:484-93.

25. Manguin S, Garros C, Dusfour I, Harbach RE, Coosemans M. Bionomics, taxonomy, and distribution of the major malaria vector taxa of Anopheles subgenus Cellia in Southeast Asia: An updated review. Infect Genet Evol. 2008;8:489-503.

26. Christophers SR. The fauna of British India, including Ceylon and Burma, Vol IV., Diptera, Family Culicidae, Tribe Anophelini London: Taylor and Francis. 1933;371 pp.

27. Surendran SN, Singh OP, Jude PJ, Ramasamy R. Genetic evidence for malaria vectors of the Anopheles sundaicus complex in Sri Lanka with morphological characteristics attributed to Anopheles subpictus species B. Malar J. 2010;9:343. 
28. Surendran SN, Sarma DK, Jude PJ, Kemppainen P, Kanthakumaran N, Gajapathu K et al. Molecular characterization and identification of members of the Anopheles subpictus complex in Sri Lanka. Malaria J. 2013;12:304.

29. Suguna, SG. Cytological and morphological evidences for sibling species in Anopheles subpictus Grassi. J commun Dis. 1982;14:1-8.

30. Wilai P, Ali RSM, Saingamsook J, Saeung A, Junkum A, Walton C, Harbach RE, Somboon P. Integrated systematics of Anopheles subpictus (Diptera: Culicidae) in the Oriental Region, with emphasis on forms in Thailand and Sulawesi, Indonesia. Acta Tropica. 2020;208:1-8.

31. Kaura T, Sharma M, Chaudhry S, Chaudhry A. Sequence polymorphism in spacer ITS2 of Anopheles (Cellia) subpictus Grassi (Diptera: Culicidae). Caryologia. 2010;63:124-33.

32. Chattopadhyay A, Paul S, Banerjee PK. Sequence variation in spacer ITS 2 of An. subpictus in rural and urban populations of West Bengal. Journal of international academic research for multidisciplinary. 2013;9(1):502-512.

33. Chhilar JS, Chaudhry S. Phylogenetic analysis of Anopheles (Cellia) subpictus Grassi using rDNA-ITS2 Sequence. Proc Zool Soc. 2012;65:1-10.

34. Eickbush TH, Eickbush DG. Finely orchestrated movements: evolution of the ribosomal RNA genes. Genetics. 2007;175:477-485.

35. Hwang UW, Kim W. General properties and phylogenetic utilities of nuclear ribosomal DNA and mitochondrial DNA commonly used in molecular systematics. Korean J Parasitol. 1999; 37:4:215-28.

36. Beebe NW. DNA barcoding mosquitoes: advice for potential prospectors Parasitology. 2018;145:622-633.

37. Wiemers M, Fiedler K. Does the DNA barcoding gap exist? - a case study in blue butterflies (Lepidoptera: Lycaenidae). Front Zool. 2007;4:8.

38. Meier R, Shiyang K, Vaidya G, Ng PK. DNA barcoding and taxonomy in Diptera: a tale of high intraspecific variability and low identification success. Syst Biol. 2006;55:715728.

39. Beebe NW. DNA barcoding mosquitoes: advice for potential prospectors Parasitology. 2018;145:622-633.

40. Reid JA. Anopheline Mosquitoes of Malaya and Borneo. Studies from the Institute for Medical Research. Malaysia, No.31, 1968;520 pp.

41. Coen ES, Strachan T, Dover G. Dynamics of concerted evolution of ribosomal DNA and histone gene families in the melanogaster species subgroup of Drosophila; J. Mol. Biol. $1982 ; 158: 17-35$. 
42. Singh OP, Chandra D, Nanda N, Htun PT, Adak T, Subbarao SK, Dash AP. On the conspecificity of Anopheles fluviatilis S with Anopheles minimus C. J Biosci. 2006;31:671-77.

43. Thompson JD, Higgins DG, Gibson TJ, Clustal W. Improving the sensitivity of progressive multiple sequence alignment through sequence weighting, position specific gap penalties and weight matrix choice. Nucleic Acids Res.1994;22:4673-80.

44. Swofford DL. PAUP: Phylogenetic Analysis Using Parsimony (and Others Methods) Version 4.0b10. D. L., Sinauer Associates, Sunderland, MA. 2002.

45. Posada D, Crandall KA. MODELTEST: testing the model of DNA substitution. Bioinformatics. 1998;14:817-8.

46. Adak T, Kaur S, Singh OP. Comparative susceptibility of different members of Anopheles culicifacies complex to Plasmodium vivax. Trans R Soc Trop Med Hyg. 1999;93:573-7.

47. Kaur S, Singh OP, Adak T. Susceptibility of species A, B, C of Anopheles culicifacies complex to Plasmodium yoelii yoelii and Plasmodium vinckei petteri infections. J Parasitol. 2000;86:1345-8.

48. Raghavendra K, Vasantha K, Subbarao SK, Pillai MK, Sharma VP. Resistance in Anopheles culicifacies sibling species B and C to malathion in Andhra Pradesh and Gujarat States, India. J Am Mosq Control Assoc. 1991;7:255-259.

49. Raghavendra K, Subbarao SK, Vasantha K, Pillai MK, Sharma VP. Differential selection of malathion resistance in Anopheles culicifacies A and B (Diptera: Culicidae) in Haryana State, India. J Med Entomol. 1992;29:183-7.

50. Subbarao SK, Vasantha K, Sharma VP. Responses of Anopheles culicifacies sibling species A and B to DDT and $\mathrm{HCH}$ in India: implications in malaria control. Med Vet Entomol. 1988;2:219-23.

51. Surendran SN, Jude PJ, Weerarathne TC, Karunaratne SHPP, Ramasamy R. Variations in susceptibility to common insecticides and resistance mechanisms among morphologically identified sibling species of the malaria vector Anopheles subpictus in Sri Lanka. Parasit Vectors. 2012;5:34.

52. Joshi H, Vasantha K, Subbarao SK, Sharma VP. Host feeding pattern of Anopheles culicifacies species A and B. J Am Mosq Control Assoc. 1988;4:248-51.

53. Nanda N, Joshi H, Subbarao SK, Yadav RS, Shukla RP, Dua VK, Sharma VP. Anopheles fluviatilis complex: host feeding pattern of species S, T and U. J Am Mosq Control Assoc. 1996;12:147-9.

54. Kumari S, Das S, Mahapatra N. Anopheles subpictus B and its role in transmission of 
malaria in Odisha, India. Trop Biomed. 2013;30:710-17.

55. Chatterjee S, Chandra G. Role of Anopheles subpictus as primary vector of malaria in an area in India. Japan J Trop Med Hyg. 2000;28:177-81.

56. Kulkarni SM. Detection of sporozoites in Anopheles subpictus in Baster district, Madhya Pradesh. Indian J Malariol. 1983;20:159-60.

57. Singh OP, Dykes CL, Sharma G, Das MK. L1014F-kdr mutation in Indian Anopheles subpictus arising from two alternative transversions in the voltage gated sodium channel and a single PIRA-PCR for their Detection. J Med Entomol. 2015;52:24-7

58. Zarowiecki M, Linton YM, Post RJ, Bangs MJ, Htun PT, Hlaing T et al. Repeated landmass reformation limits diversification in the widespread littoral zone mosquito Anopheles sundaicus sensu lato in the Indo-Oriental Region. Mol Ecol. 2014;23:2573-89.

59. Syafruddin D, Lestari YE, Permana DH, Asih PBS, St. Laurent B, Zubaidah S, et al. Anopheles sundaicus complex and the presence of Anopheles epiroticus in Indonesia. PLoS Negl Trop Dis. 2020;14:e0008385.

60. Tyagi BK, Hiriyan J, Tewari SC, Ayanar K, Samuel P, Paramasivan R. Description of a new species, Anopheles pseudosundaicus (Diptera: Culicidae) from Kerala, India. Zootaxa. 2009;2219:49-60.

61. Beebe NW, Saul A. Discrimination of all members of the Anopheles punctulatus complex by polymerase chain reaction - restriction fragment length polymorphism analysis. Am J Trop Med Hyg. 1995;53:478-81.

62. Campbell BC, Steffen-Campbell JD, Werren JH. Phylogeny of the Nasonia species complex (Hymenoptera: Pteromalidae) inferred from an internal transcribed spacer (ITS2) and 28S rDNA sequences. Insect Mol Biol. 1993;2:225-37.

63. Litvaitis M. K, Nunn G. Thomas, W. K., Kocher, T. D. A molecular approach for the identification of Meiofaunal turbellarians (Platyhelminthes, Turbellaria). Mar. Biol. 1994;120;437-42.

64. Sharpe RG, Harbach RE, Butlin RK. Molecular variation and phylogeny of members of the Minimus group of Anopheles subgenus Cellia (Diptera: Culicidae). Syst Entomol. $2000 ; 25: 263-72$.

Table 1 List of primers used for DNA sequencing

\begin{tabular}{lll}
\hline Primers' name & Neucleotide sequence $\left(\mathbf{5}^{\prime} \mathbf{- 3}\right)$ & Reference \\
\hline ITS2A & TGT GAA CTG CAG GAC ACA T & Beebe and Saul,1995 [61] \\
ITS2B & TAT GCT TAA ATT CAG GGG GT & Beebe and Saul,1995 [61] \\
\hline
\end{tabular}




\begin{tabular}{lll}
\hline D2A & AGT CGT GTT GCT TGA TAG TGC AG & Campbell et al.,1993 [62] \\
D2B & TTG GTC CGT GTT TCA AGA CGG G & Campbell et al.,1993 [62] \\
D3A & GAC CCG TCT TGA AAC ACG GA & Litvaitis et al.,1994 [63] \\
D3B & TCG GAA GGA ACC AGT TAC TA & Litvaitis et al.,1994 [63] \\
COIIF & TCT AAT ATG GCA GAT TAG TGC A & Sharpe et al., 2004 [64] \\
COIIR & ACT TGC TTT CAG TCA TCT AAT G & Sharpe et al., 2004 [64] \\
SP6 & ATTTAGGTGACACTATAG & Universal primer \\
T7 & TAATACGACTCACTATAGGG & Universal primer \\
\hline
\end{tabular}

Table 2 Number of mosquitoes identified into molecular forms of An. subpictus and An. sundaicus based on the rDNA (ITS2 and 28S-D2-D3) sequences and AS-PCR

\begin{tabular}{|c|c|c|c|c|}
\hline \multirow[t]{2}{*}{ Locality } & \multirow[t]{2}{*}{ Molecular forms } & \multicolumn{2}{|c|}{ DNA sequencing } & \multirow[t]{2}{*}{ AS-PCR* } \\
\hline & & ITS2 & 28S-D2-D3 & \\
\hline Nuh, India & An. subpictus Form A & 4 & 4 & 86 \\
\hline Ranchi, India & An. subpictus Form A & 63 & 19 & 15 \\
\hline Borio, India & An. subpictus Form A & 2 & 2 & 10 \\
\hline Alwar, India & An. subpictus Form A & 3 & 3 & 12 \\
\hline Jodhpur, India & An. subpictus Form A & 2 & 7 & 7 \\
\hline Gadchiroli, India & An. subpictus Form A & 4 & 4 & 25 \\
\hline \multirow[t]{2}{*}{ Chilka, India } & An. subpictus Form A & 3 & 3 & 62 \\
\hline & An. subpictus Form B & 8 & 8 & 618 \\
\hline Goa, India & An. subpictus Form B & 2 & 2 & 5 \\
\hline \multirow[t]{2}{*}{ Puducherry, India } & An. subpictus Form A & 8 & 8 & 59 \\
\hline & An. subpictus Form B & 5 & 5 & 73 \\
\hline \multirow[t]{2}{*}{ Sri Lanka } & An. subpictus Form A & 22 & 13 & 16 \\
\hline & An. subpictus Form B & 6 & 6 & 44 \\
\hline Portblair, A\&N Island & An. subpictus Form C & 5 & 5 & ND \\
\hline \multirow[t]{3}{*}{ Carnicobar, A\&N Island } & An. subpictus Form C & 5 & 5 & ND \\
\hline & An. sundaicus D (variant III\#) & 12 & 12 & ND \\
\hline & An. epiroticus (variant I\#) & 1 & 1 & ND \\
\hline Myanmar & An. epiroticus (variant I\#) & 4 & 4 & ND \\
\hline
\end{tabular}

* Assignment of Form B or C of An. subpictus in a specific locality was done on the basis of molecular form present in the area as determined by DNA sequencing.

\# Designation of variants as per Dusfour et al. [24]

$\mathrm{ND}=$ not done 
Table 3 Pairwise distances (Kimura-2 parameter model) (below diagonal) and nucleotide substitution (above diagonal) between different molecular forms of An. subpictus and An. sundaicus based on ITS2 and 28S-D2-D3. Sub_A=An. subpictus Form A, Sub_B=An. subpictus Form B, Sub_C=An. subpictus Form C, Epi = An. epiroticus (variant I), Sun_D = An. sundaicus D (variant III)

\begin{tabular}{llllll}
\hline & Sub_A & Sub_B & Sub_C & Epi & Sun_D \\
\hline Sub_A & - & $\mathbf{1 0 4}$ & $\mathbf{1 0 6}$ & $\mathbf{1 0 0}$ & $\mathbf{1 0 1}$ \\
Sub_B & $\mathbf{0 . 0 6 5}$ & - & 9 & 9 & 10 \\
Sub_C & $\mathbf{0 . 0 6 6}$ & 0.005 & - & 8 & 9 \\
Epi & $\mathbf{0 . 0 6 3}$ & 0.005 & 0.005 & - & 1 \\
Sun_D & $\mathbf{0 . 0 6 3}$ & 0.006 & 0.005 & 0.001 & - \\
\hline
\end{tabular}

Table 4 Nucleotide substitution (above diagonal) and pairwise distances (Kimura-2 parameter model) (below diagonal) and between different molecular forms of An. subpictus and An. sundaicus based on ITS2 sequences. Sub_A=An. subpictus Form A, Sub_B=An. subpictus Form B, MT068425 (Thailand), Sub_C=An. subpictus Form C, MT068436 (Indonesia), , Epi $=$ An. epiroticus $($ variant I), Sun_D = An. sundaicus D (variant III), Ind=An. indefinitus

\begin{tabular}{lllllllll}
\hline & Sub_A & Sub_B & MT068425 & Sub_C & MT068436 & Epi & Sun_D & Ind \\
\hline Sub_A & - & $\mathbf{5 1}$ & $\mathbf{4 9}$ & $\mathbf{5 2}$ & $\mathbf{5 2}$ & $\mathbf{4 7}$ & $\mathbf{4 8}$ & $\mathbf{4 8}$ \\
Sub_B & $\mathbf{0 . 1 0 3}$ & - & 2 & 4 & 4 & 5 & 6 & 3 \\
MT068425 & $\mathbf{0 . 0 9 9}$ & 0.004 & - & 4 & 4 & 3 & 4 & 1 \\
Sub_C & $\mathbf{0 . 1 0 5}$ & 0.008 & 0.008 & - & 0 & 7 & 8 & 5 \\
MT068436 & $\mathbf{0 . 1 0 5}$ & 0.008 & 0.008 & 0 & - & 7 & 8 & 5 \\
Epi & $\mathbf{0 . 0 9 4}$ & 0.010 & 0.006 & 0.013 & 0.013 & - & 1 & 4 \\
Sun_D & $\mathbf{0 . 0 9 7}$ & 0.011 & 0.008 & 0.015 & 0.015 & 0.002 & - & 5 \\
Ind & $\mathbf{0 . 0 9 7}$ & 0.006 & 0.002 & 0.009 & 0.009 & 0.008 & 0.010 & - \\
\hline
\end{tabular}


1 Table 5 Distribution of An. subpictus sibling species based on number of float-ridges on eggs and their molecular forms

\begin{tabular}{lllllllllll}
\hline Localities & \multicolumn{6}{l}{ Assigned sibling species based on mode number of float-ridges (shown in parenthesis) and their molecular forms } \\
& \multicolumn{2}{l}{ Species B (16-20) } & \multicolumn{2}{l}{ Species D (21-24) } & \multicolumn{2}{c}{ Species C (25-29) } & \multicolumn{2}{c}{ Unassigned (30) } & Species A (31-36) \\
& Form A & Form B & Form A & Form B & Form A & Form B & Form A & Form B & Form A & Form B \\
\hline Nuh & - & - & 7 & - & 46 & - & 1 & - & - & - \\
Delhi & - & - & 1 & - & 5 & & 4 & - & 4 & - \\
Jodhpur & - & - & - & - & 4 & - & 2 & - & - & - \\
Ranchi & - & - & - & - & 1 & - & - & - & - & - \\
Chilka & - & 49 & 4 & - & 11 & - & - & - & - & - \\
Puducherry & - & 2 & 4 & - & 10 & - & - & - & - & -
\end{tabular}


Table 6 Relative prevalence of An. subpictus Form A and B in monsoon and post-monsoon season in areas surrounding Chilka Lake (brackish water lagoon) and Puducherry (coastal area).

\begin{tabular}{|c|c|c|c|c|}
\hline \multirow[t]{2}{*}{ Location } & \multirow[t]{2}{*}{ Season } & \multirow[t]{2}{*}{ Date of collection } & \multicolumn{2}{|c|}{ Number of samples identified as } \\
\hline & & & Form A* & Form B* \\
\hline \multirow{6}{*}{$\begin{array}{l}\text { Chilka Lake, Odisha, } \\
\text { India }\end{array}$} & Post- & Feb 2017 & 0 & $84(100)$ \\
\hline & monsoon & & & \\
\hline & & Feb 2018 & 0 & $94(100)$ \\
\hline & Monsoon & Sept-Oct 2017 & $4(4.76)$ & $80(95.24)$ \\
\hline & & Sept 2018 & $16(6.58)$ & $227(93.42)$ \\
\hline & & July-Aug 2019 & $11(7.64)$ & $133(92.36)$ \\
\hline \multirow{3}{*}{$\begin{array}{l}\text { Puducherry, Tamil Nadu, } \\
\text { India }\end{array}$} & Post- & Feb-Mar 2020 & $8(11.76)$ & $60(88.24)$ \\
\hline & monsoon & & & \\
\hline & Autumn & Nov 2019 & $51(79.68)$ & $13(20.31)$ \\
\hline
\end{tabular}

* Figures in parenthesis represent percentage proportion 


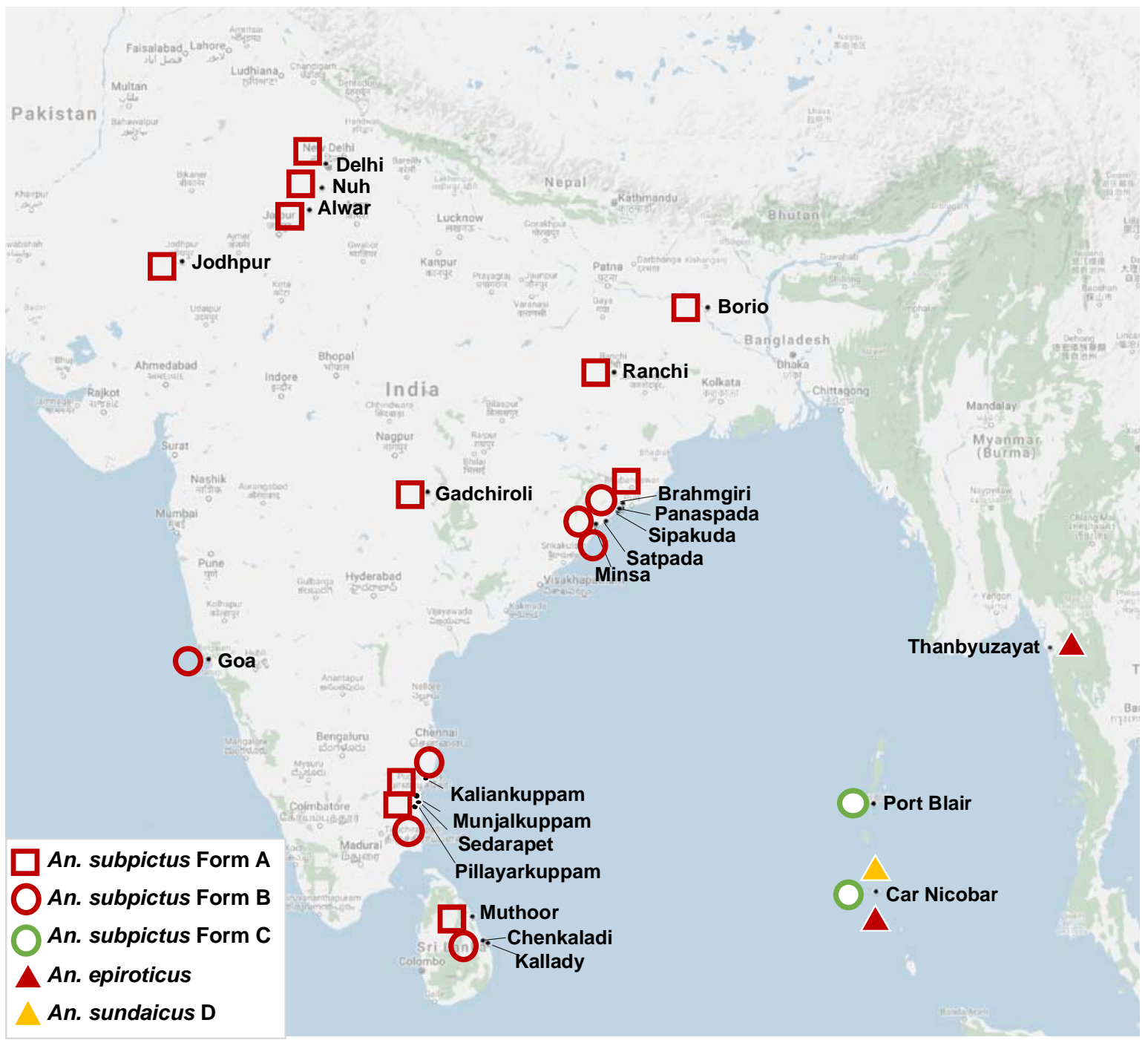

Figure 1 Map showing geographical locations of study sites and distribution of different molecular forms of An. subpictus s.l. and An. sundaicus s.l. 


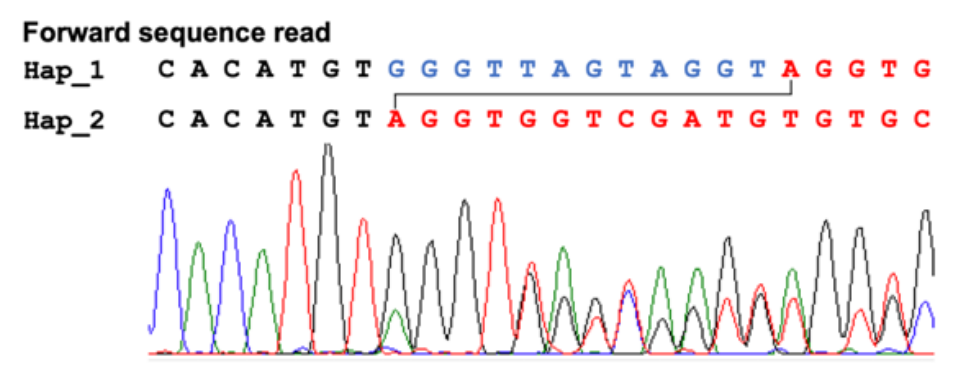

Reverse sequence read

Hap_1 C A C A T G T G G G T T A G T A G G T A G G T G

Hap_2 G G T G G T A C A A C C C A C A T G T A G G T G

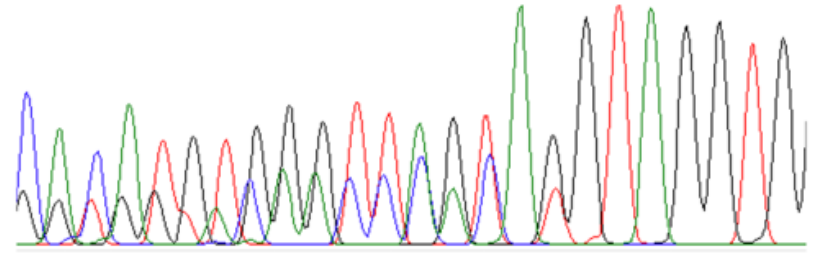

Figure 2 DNA sequence chromatograms of a portion of ITS2 (Forward and reverse) of An. subpictus form A, having indel in one haplotype. Hap_1 and Hap_2 in this figure represent haplotype 1 and 2 , respectively.

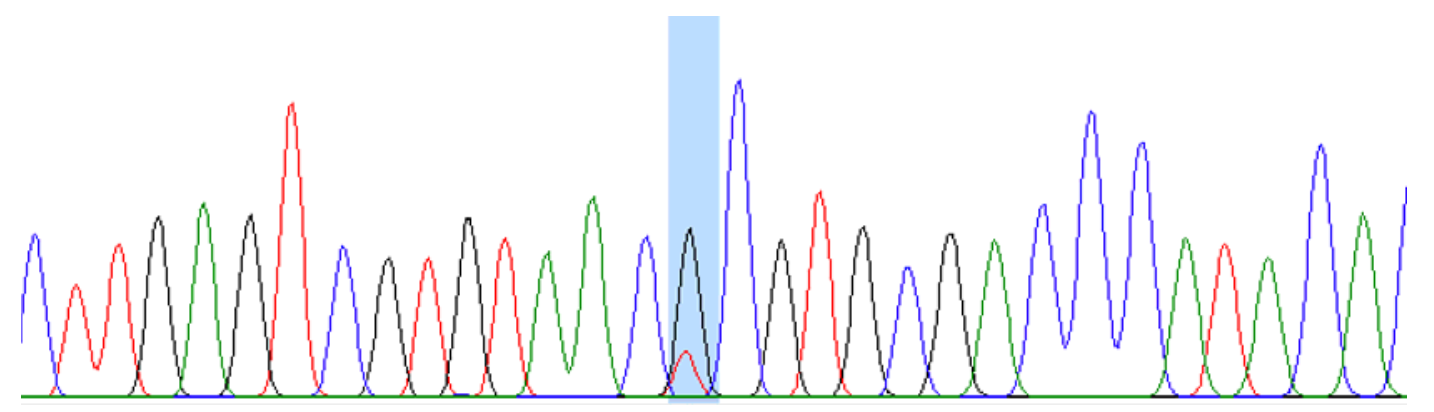

Figure 3 Portion of DNA chromatogram of ITS2 sequence of An. epiroticus from Car Nicobar island showing mixed bases (highlighted) at nucleotide base position 518 (base position as per Zarowiecki et al. 2014 [58]) 


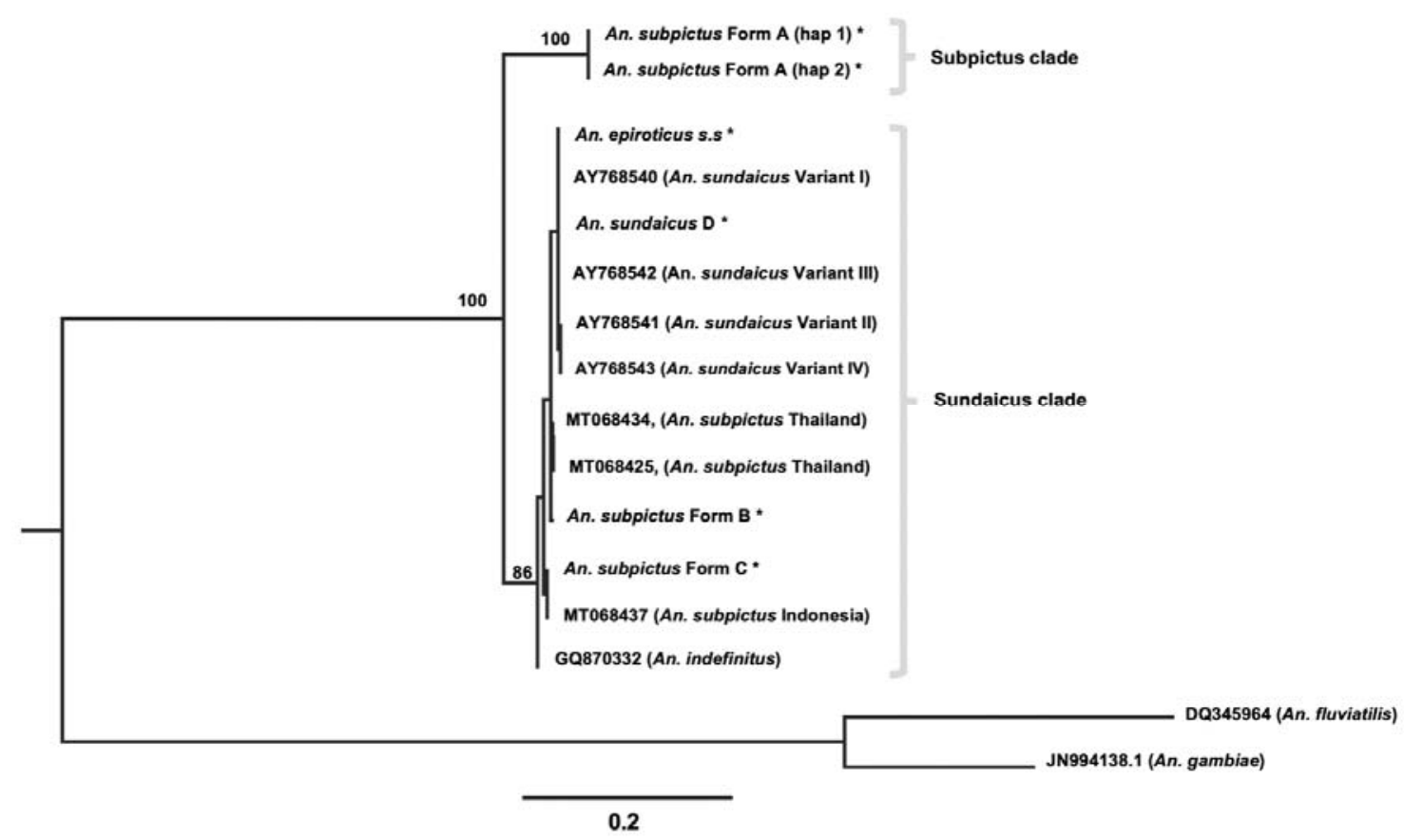

Figure 4 Maximum Likelihood (ML) rooted tree of different molecular forms of An. subpictus and An. sundaicus complex based upon ITS2 sequence data. Numbers at nodes are ML bootstrap values (only $>80$ are shown). The sequence name with astricks $(*)$ are the sequences generated in this study.

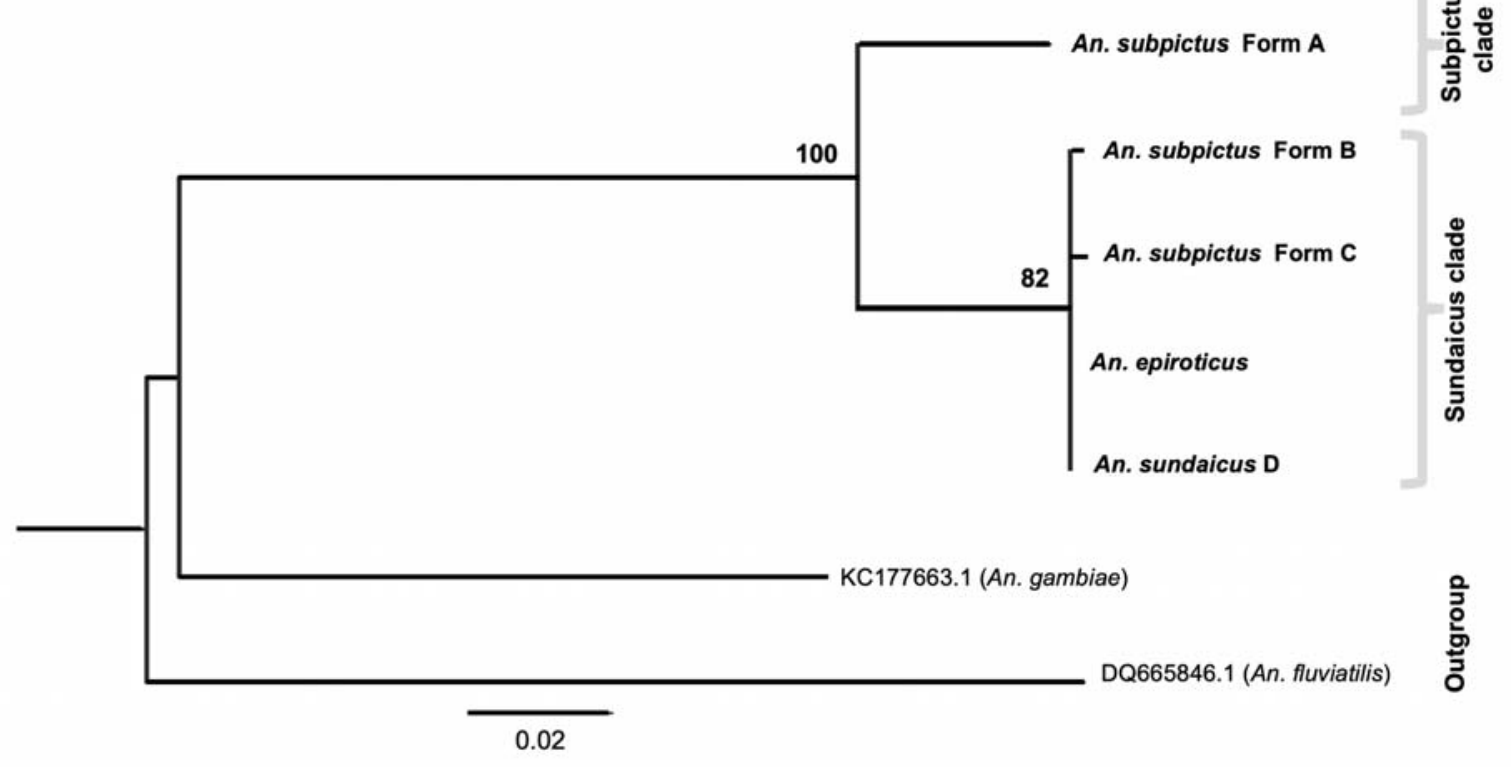

Figure 5 Maximum Likelihood (ML) rooted tree of different molecular forms of An. subpictus and An. sundaicus complex based upon 28S-D2-D3 sequences. Numbers at nodes are ML bootstrap values (only $>80$ are shown). 


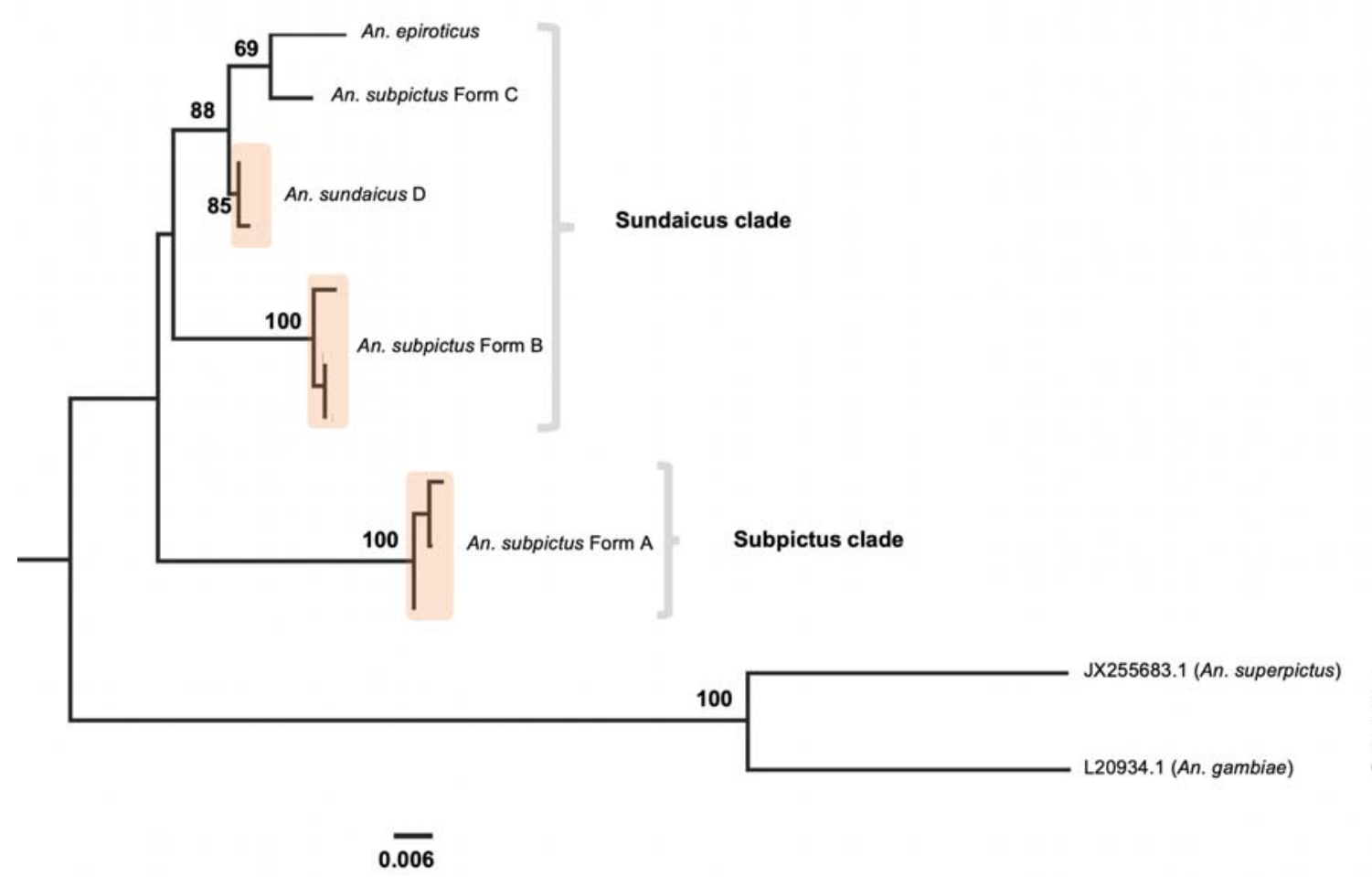

Figure 6 Maximum Likelihood (ML) rooted tree of different molecular forms of An. subpictus and An. sundaicus complex based upon COII sequences. Numbers at nodes are ML bootstrap values (only $>50$ are shown). 


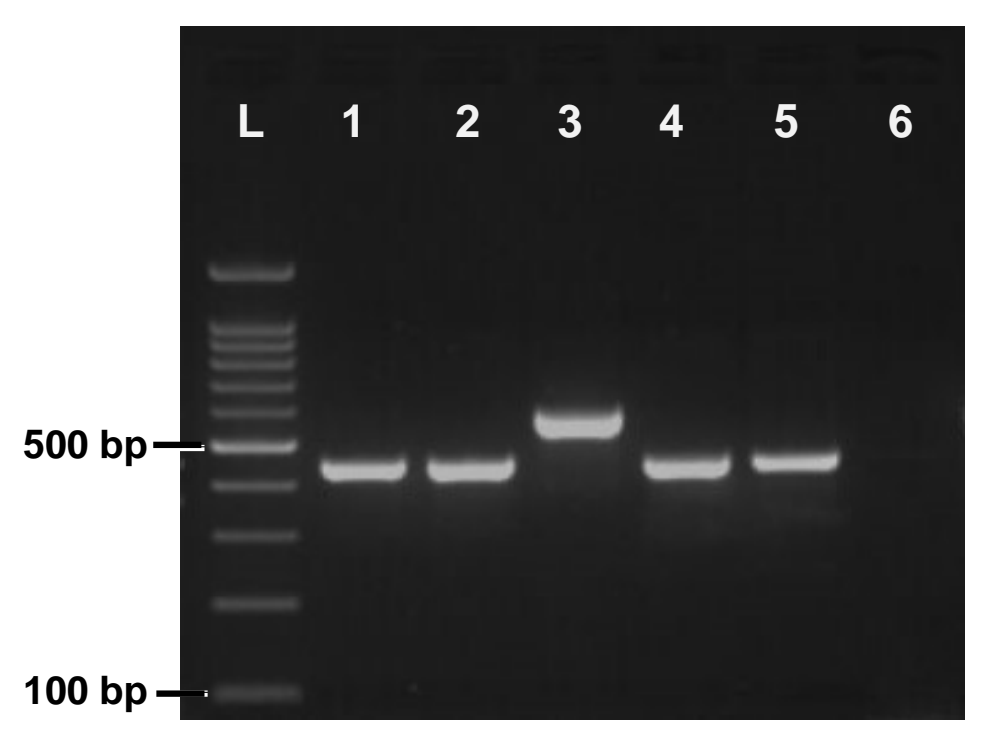

Figure 7 Gel photograph of allele-specific PCR used for the identification of molecular forms A and B in mainland India where only form A and B are prevalent. Lanes L: 100 bp DNA ladder, lane 1: An. subpictus Form B, lane 2: An. subpictus Form C, lane 3: An. subpictus Form A, lane 4: An. sundaicus D, lane 5: An. epiroticus, lane 6: negative control.

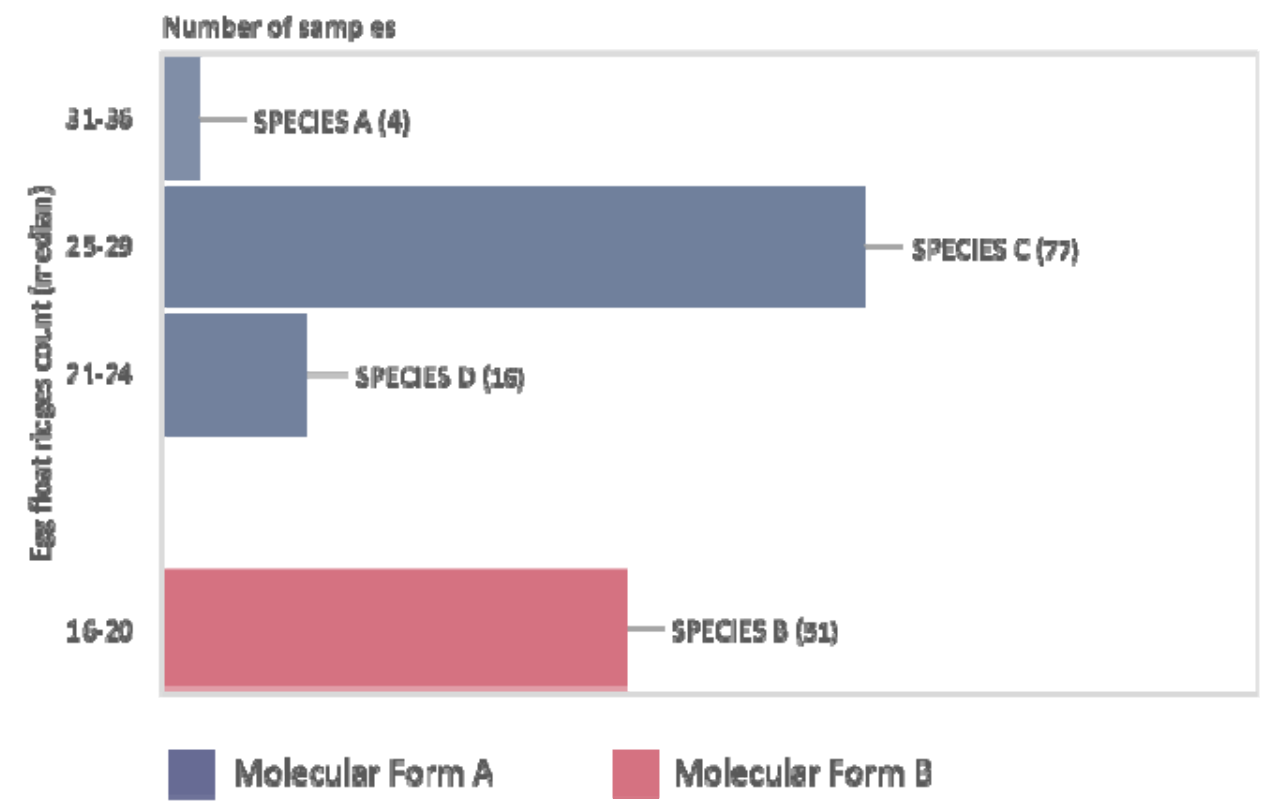

Figure 8 Classification of samples collected from mainland India as sibling species based on mode number of float-ridges [18] and their molecular forms. Details of locations and number of samples have been provided in Table 5. 


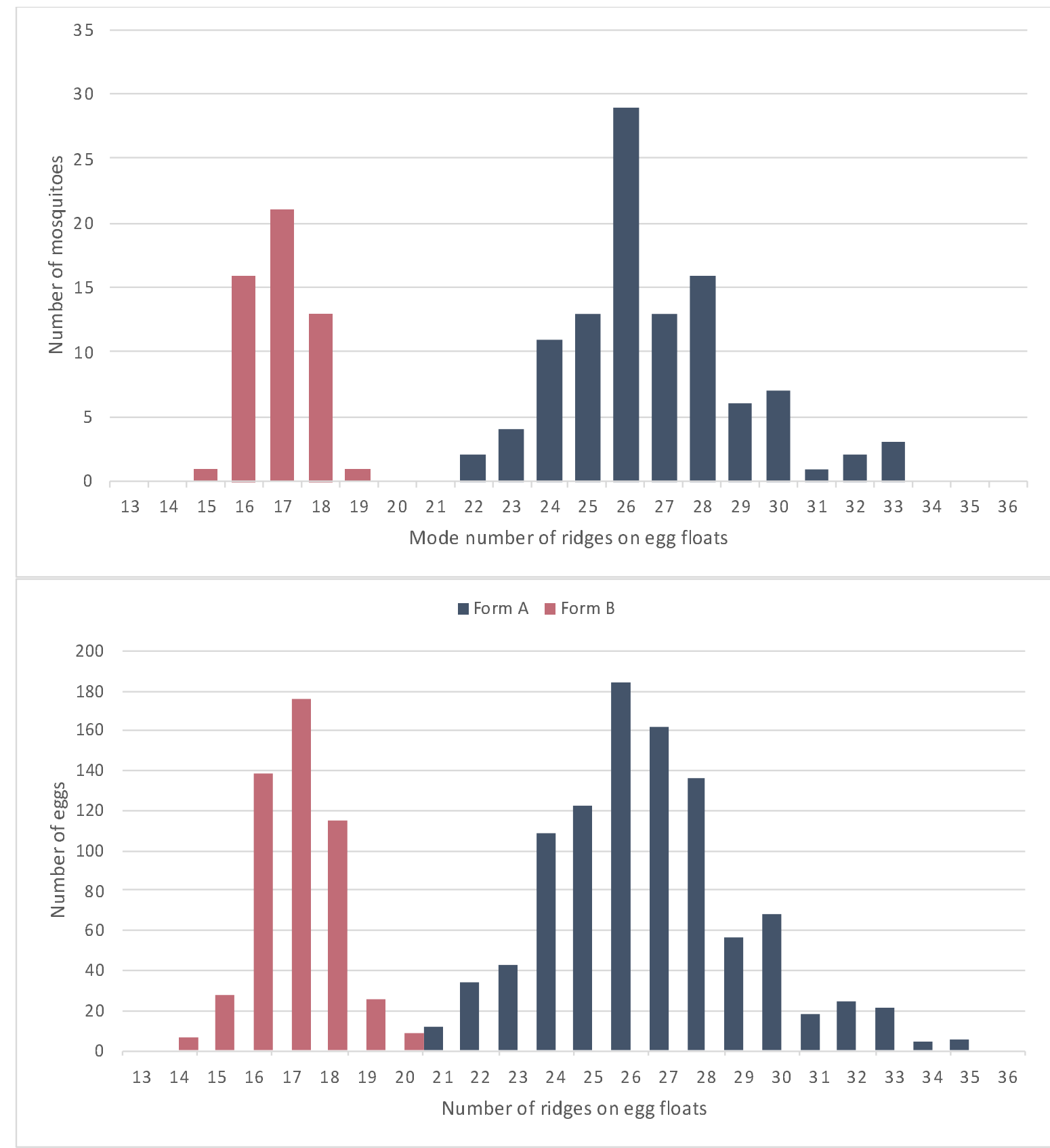

Figure 9 The frequency distribution of mosquitoes with mode number of floats-ridges (a) and eggs with number of float-ridges (b), among molecular form A and B prevalent in mainland India 